\title{
Reporting results back in Health and demographic surveillance systems (HDSS): an ethical requirement and a strategy for improving health behaviours
}

\author{
Nathalie Mondain ${ }^{\mathrm{a}}$,Valérie Delaunay ${ }^{\mathrm{b}}$ and Valérie Ouédraogo ${ }^{\mathrm{c}}$ \\ a School of sociological and anthropological studies, University of Ottawa \\ 'Institut de recherche pour le développement, LPED, UMR151 IRD/Aix-Marseille Université \\ 'School of Social Work, Grant MacEwan University \\ Nathalie.mondain@uottawa.ca
}

\begin{abstract}
This paper addresses the issue of reporting results back in Health and demographic surveillance systems (HDSS). In these particular research platforms, populations are constantly solicited through the longitudinal demographic follow-up and additional surveys. Therefore, reporting results back directly to participants should be considered as a strong ethical requirement. However, like in most health oriented research, results are mostly disseminated among decision makers and local authorities. Therefore, HDSS residents increasingly question the objectives of these studies. Using a participatory approach, 3 days were organized in 2015 to report back findings based on 50 years of research on population, health and environment in the Niakhar HDSS in Senegal. Drawing from the evaluation conducted among a sample of participants to the event, we show that beyond the ethical dimension, such activities may also contribute to change populations' attitudes to research practices and further influence individuals' health behaviors at the local level.
\end{abstract}

Keywords: Demographic and health surveillance systems; Ethics; Report results back; behavioral change; Participatory approach

\section{Introduction}

Health and demographic surveillance systems (HDSS) are challenging for a variety of reasons essentially due to the constraining data collection design. If the great potential for improving data quality on health has reached a consensus among researchers and decision makers as shown by the significant increase of such sites during the past decades (see http://www.indepth-network.org/) as well as the growing number of high quality scientific publications based on these data, issues regarding research practices have also been raised with an emphasis on ethics. During a workshop on ethics in HDSS held in Moundasso, Burkina Faso in 2006 (Arduin et al, 2006: http://www.lped.fr/lMG/pdf/Note sur Ethiquefinal 02-07-07.pdf), the specific dimension of reporting results back to the populations and to policy and development actors was discussed as falling under the principles of beneficence and justice. Although research conducted in these sites should be - and is - beneficial for the populations, it remains difficult for them to identify immediate positive effects from the
HDSS activities on their daily life conditions. In addition, participants to this workshop agreed that populations generally remained poorly informed of the research outcomes although they are constantly solicited for both the longitudinal follow-up and specific research projects. Therefore, reporting results back appeared as an important ethical requirement. In addition, as shown by a research project conducted on this issue in 2006-2007 (Mondain et al, 2010) ${ }^{i}$, reporting scientific results back to lay persons, beyond the ethical aspect may also have an effect on the quality of the data collected. The study highlighted how participants were willing to better understand the purposes of the studies conducted among them because "it would help them to better answer the questions" (Mondain et al, 2010). In other words, researchers would potentially get more detailed information as participants would better relate the purposes of the different projects taking place in their area of residence to the health and demographic transformations they are observing even if occurring on the long run. We argue in this paper that such awareness and increased 
knowledge on how health patterns can be improved by research is likely to facilitate the participation of populations to studies to which they might be initially reluctant and may also constitute an incentive for them to modify health practices at the individual and community levels.

One important challenge, addressed in the 2006-2007 project (but not operationalized) was to design appropriate communication tools in order to report results back directly to the populations and not solely to health authorities and local decision makers. Inspired by other experiences conducted in other West African countries (Hertrich et al, 2011), an innovative approach was used for the design of an event aiming at reporting back results from 50 years of research in the Niakhar HDSS in 2014-2015 to an audience gathering a great diversity of the local society's representatives.

We will first briefly cover the main issues related to ethics in research in the specific context of HDSS, and then describe the experience conducted in the Niakhar site before providing an overview of the impacts of the whole process on participants.

\section{Literature review and key issues}

In this section we will first provide a brief description of what a HDSS is and how it works as it raises both methodological and ethical issues by its specific and unique research design. We then explore the different avenues that ground the efforts made in reporting scientific results back using a participatory approach.

\section{Health and demographic surveillance systems (HDSS) - an overview}

The main objective of a HDSS is to conduct a longitudinal demographic and health follow-up within a geographically circumscribed population in a rural or urban area. At the implementation of a HDSS, a census is conducted to identify each household as well as the number of residents composing it. Once this baseline is established, the longitudinal demographic and health followup starts, with regular visits (usually one or more per year) in each household where one member, generally the head of the household, is mobilized to update the demographic and health information since the last visit. The frequency of the visits depends on the objectives of the project as well as on the financial means available. In addition to the demographic followup, a HDSS also constitutes a research plateform open to various projects under the approval of the coordinating team and in collaboration with the HDSS research staff. Consequently, the residents of such sites are solicited to answer to the standardized questions of the demographic follow-up on a regular basis as well as to participate to surveys and other studies on related issues conducted among a sample of the HDSS population.

HDSS have started to be implemented since the early 1960s (mostly in Asia and sub-Saharan Africa) as is the case for the Niakhar site (Delaunay et al, 2013). One of the main motivations to implement a HDSS is to measure the impact of health interventions among the population under study, so most of the scientific approaches used are health oriented with demographers or other social scientists collaborating with physicians and researchers in public health. However, some sites, due to their long lasting existence (like Niakhar in Senegal or the Navrongo HDSS in Ghana), have opened to other fields of research to explore more socioanthropological dimensions in order to provide more depth in the understanding of demographic and health behaviours and change (Madhavan et al, 2007).

Several actors are involved in a HDSS, and beyond the residents and the researchers, interviewers and other local field workers constitute a key group if not the key informants and facilitators. In rural HDSS most of the field workers in charge of the demographic follow-up are natives from the villages and live there with their families. Other research staffs interviewers for punctual projects, facilitators, interpreters - are generally hired locally based on their reputation gained by working with various research teams across the past years. Researchers' presence and frequency of visits will depend on various factors, including the discipline at stake (an anthropologist is likely to choose a constant immersion with the population compared to a physician for example), their status in the project (is the researcher alone or working with a team where collaborators can share the tasks?), etc. In most cases, unless the researcher masters the local language, the local field-staffs remain key intermediaries between him-her and the populations. This leads to a paradoxical situation where research activities are constantly present through various forms of data collection but not necessarily with the researchers themselves. The lack of immersion from some researchers may spread confusion in residents' perceptions of who is responsible and knowledgable for the data collection process and its outcomes.

Therefore, HDSS face complex methodological and ethical challenges and reporting results back directly to the 
communities has become a major preoccupation among researchers. This preoccupation is based on several researchers' perception that HDSS residents express weariness and sometimes reluctance to participate as they feel they are constantly solicited without a clear understanding of the purposes of such intense data collection processes. Therefore, an increasing number of HDSS researchers have decided to extend the Health Ethical committee board's requirements (exclusively oriented to medical sciences) to other areas of research (including demographic and socioanthropological research) with a specific attention to the respect for the principle of justice and inclusiveness. In this paper we show that reporting results back directly to the communities by designing context sensitive activities and using a participatory approach contributes to improve HDSS residents' feeling that they are respected as research subjects and therefore are more willing to participate. We also emphasize the importance to nurture a constant dialogue between researchers and populations. Our view is that reporting results back directly to the participants may constitute a way to reconcile the problems related to informed consent, participation to a research and its potential benefits.

\section{Reporting scientific results back to lay people: an ethical requirement}

A project conducted in 5 HDSS sites in Senegal and Burkina Faso in 2006-2007 (see endnote 1) focusing on the ethical issues raised by these particular research platforms, showed the need for residents to have a better understanding of the "path to information", from data collection and management to the final results and their concrete outcomes (Mondain and Bologo, 2009; Mondain et al, 2010). For example, blood samples involved by some medical studies are often not well accepted by the populations leading to intense negotiations between them and fieldworkers. Verbal autopsiesii, that are often conducted based on the information drawn from the longitudinal follow-up, also constitute a complex issue with respondents being extremely reluctant to participate and fieldworkers often emotionally moved by the distress expressed by some respondents when they are asked to describe retrospectively the whole process that has led to the death of someone close to them. In this particular case, explanations that would highlight how verbal autopsies have informed local health authorities on specific diseases for example could clarify the pertinence of such data collection tools and improve populations' participation. Addressing populations' expectations and needs for more information may thus be a key issue for the continuation of these programs especially as HDSS provide researchers with a longer time frame to plan their agendas along the lines of global health and development objectives aimed to be applied locally.

In the specific case of HDSS, reporting results back to participants have two major advantages. A first one is that it may improve the contacts and thus the collaboration between researchers and participants. As mentioned earlier, in a HDSS, residents are likely to have high expectations because of the long lasting presence of research teams in their environment. However, it is not the purpose of HDSS to translate their results into action; rather, the findings are usually transmitted to decision-making actors. This leads to populations' misunderstanding of the researchers' role. Therefore, opportunities to (re) establish and maintain a dialogue between the different actors involved (populations, field workers and researchers) would contribute to populations' understanding of the research process and its potential in improving the community's life conditions. Not only this could increase their motivation to participate, but also it may improve the informed consent process for future projects and follow-up rounds as people will be more active in requesting more information about the research for which they are solicited.

Another advantage of reporting results back is that participants, by being directly informed about the findings and implications of those in their daily lives may modify their attitudes and behaviour accordingly. In this perspective, reporting results back may complement knowledge transfer processes that are generally meant to target practitioners and decision makers even if the ultimate objective is to reach the greater public (Siron et al, 2015).

Madhavan et al (2007) have pointed to the need of a more participatory approach in HDSS despite the challenge it represents in a context where neither the key research actors nor the populations themselves are familiar to it. However, by involving a wider range of actors including field workers and key informants within the population, researchers may get a more accurate insight of how their activities are perceived by the populations and thus how it may influence the way residents answer to their questions. Being aware of these perceptions could help researchers to improve their explanations of the research process and in 
some cases to adapt their project design and analytical framework (Massé, 2003; Olivier de Sardan, 2014). As such we argue that reporting back results to a broader audience contributes to a better appropriation and use of research findings by all actors at different levels: individual, household, local authorities and decision makers.

This being said, several questions arise: to whom should the results be reported back? If targeting the entire population seems essential, when it reaches over 40,000 people spread over 30 villages as is the case in the Niakhar HDSS, the logistic and financial constraints increase significantly. In that case should a sample be selected to participate to such activities and based on which criteria? Another issue relates to what should be reported back: this is especially salient in the case of long lasting HDSS where research projects in addition to the longitudinal demographic follow-up have led to a huge accumulation of data. Clearly not all the results can (and even should) be reported, but on the basis of which criteria should the selection of results be done? Finally, what are the appropriate communication channels and tools that will contribute to make research findings understandable to socially and culturally diversified audiences?

Drawing from a recent experience in the Niakhar HDSS where three days in February 2015 were dedicated to report scientific findings back accumulated over the past 50 years since its implementation, we address these questions and open the discussion on the outcomes of this way of interacting between the various actors involved in the site. More specifically we are examining to what extent the communication means designed to reach the population were adequate, whether the content covered topics that interested them or if some themes were missing. We also look at how the participation to these days has contributed to modify participants' perceptions and understanding of the research undertaken in the site and the scientific process overall from data collection to diffusion. Finally, we try to assess the extent to which participants are themselves disseminating the information and as such contribute to the sensitization of non-participants.

\section{Reporting back the results of 50 years of research: objectives and challenges}

In 2014, the Niakhar Health and demographic surveillance system (HDSS) celebrated its 50 years of implementation and 3 days were scheduled in February 2015 to report results back from the core research themes addressed during the past decades - population, health and environment. Researchers, fieldworkers and local key informants gathered together during four months to design the event.

The main objective of the event was to make the "path to information" understandable, from data collection to the dissemination of results and potential interventions. In this section, we describe the process that has led to the selection of participants and of the findings to be reported back as well as to the design the communication tools. We highlight the main issues we encountered during that process.

The Niakhar HDSS located South East from Dakar in Senegal was implemented in 1962 by ORSTOM which became IRD (Institut de recherche pour le développement) in 1998. In 1962 the HDSS was composed by 8 villages only. Since 1983 , the site was enlarged to 30 villages, its population reaching over 44,000 residents in 2014. The frequency of the visits has varied across time from periods of weekly follow-ups when important health projects were ongoing in association to large vaccination programmes in the end of the 1980s-early 1990s to periods with fewer visits ( 3 times to once a year).

For logistic and budget reasons, it was agreed that these days would constitute a first step in a more ambitious process aiming to report research findings back in each village and to all the residents. In this first step a sample of participants representing various socioeconomic groups was selected. The three main villages of the HDSS hosted one of the three days composing the whole event, gathering approximately 100-120 persons. During each day, various dimensions related to population dynamics, health and environment were covered using three communication means: a theater performance, a slide show commented in the local language (Sereer), and a period of discussion between the audience and the researchers, moderated by a researcher and a local fieldworker.

To organize the event a committee was set up with a coordinator, five IRD researchers including the HDSS leaders, and two of the local field workers in charge of the demographic follow-up and native from the Niakhar area. This committee had to establish the sample of participants, the content (what should be reported) and the format (how should it be reported).

\section{Defining the audience}

The participants were selected based on their occupation and status in the community as well 
as their residence in one of the 3 sectors of the area $\mathrm{iii}$ respectively composed by one main village (where the event took place) and its satellite villages depending on its health dispensary. In order to make sure the key local personalities would be included, one local informant was hired in each of the three villages to assist the coordinator in identifying and contact them.

It is important to note that the Niakhar HDSS is located in the Sereer-Siin region where an ancestral agricultural and farming tradition has lasted until the contemporary period. Another feature within the area is the intense circular seasonal migration to cities, mainly Dakar for young and older adults in search for additional income as agriculture is not sufficient to sustain a whole family anymore. These circular migrations have considerably modified individual behaviours, especially regarding marriage and family building. However, due to deep affective ties to their homelands, Sereer people generally keep their traditions and ways of life ongoing as much as they can. This has contribued to maintain slight socio-cultural differences between the three sectors: for example, in the Diohine sector where Christian religion is dominant combined to animism, the rituals surrounding boys' circumcision remain vivid. At the other corner of the spectrum the Toucar sector appears as more diversified with a significant Wolof community or Sereer who have embraced the Wolof culture. Toucar is also at the crossroad of different routes leading to close towns and cities in addition to the main road to Dakar. Finally, the Ngayokhem sector seems more "rural" and concerned with agriculture and environment with a strong involvement of local peasants in specialized farming associations. The fact that researchers in environmental studies have devoted time in this particular area for decades may also have contributed to shape its inhabitants' interests regarding these issues. In other words, each sector has its own 'history' which may constitute one key of interpretation of differences between residents' discourses.

In this process of constituting the sample of participants, during the 4 months prior to the event, group discussions were scheduled with residents including village chiefs and religious leaders in order to identify collectively the topics and areas of research to be covered. The coordinator and field workers shared this information with the other members of the organizing committee and the design of the event could thus be improved by pointing to key issues that populations wanted to be covered but had not initially been considered.
Every health occupations were represented: the head of the local dispensaries, community health agents, midwives, nurses, and bajenu $g o x^{i v}$. Teachers from the primary and secondary schools were also invited with their respective directors. Heads and members of local women's groups were identified and contacted as well as those from farming associations specialized in agriculture and animal breeding. Finally, all village chiefs with one or two of their councillors and the local religious leaders were invited. Most of the field workers hired on a temporary base by IRD staff or their collaborators were also asked to participate.

\section{Selecting the results to be reported.}

Through the preliminary consultations with the local representatives, a consensus emerged that people needed a better insight on the "path to information": what are the different steps from data collection to the findings and potential actions? Interestingly, despite the fact that there was a consensus among the organizing committee members that these days were a first step towards a more direct share of information with the populations, inevitably, researchers wanted to highlight findings that were important according to them although some of these results would not necessarily interest a majority of participants. However, everyone agreed, and it was also under the pressure of the local fieldworkers, that "problematic" topics such as blood sample procedures should be addressed. It was indeed important for the fieldworkers to address such issues in order to facilitate their daily work by making residents more aware of the reasons why certain research procedures are undertaken.

Clearly the task for the researchers in health was the easiest as everyone in the area is preoccupied by health issues. Interestingly, during the preparatory discussions, and reflecting the contemporary trends in population aging, several participants insisted that researchers were neglecting adult health and remained too focused on children's health despite its significant improvement across years. People who expressed this perception and preoccupation were encouraged to bring it up during the period dedicated to questions.

One challenge in presenting the various findings was to highlight the relationship between them. For example, the health improvement and spectacular decrease in the under-five mortality since the implementation of the HDSS relates to both health and demographic change. Another challenge relates to the role played by the HDSS researchers 
(here referred to as "IRD") in such changes. The observed improvements in health especially are with no doubt largely due to the scientific activities conducted by generations of researchers in the area; however, researchers do not initiate interventions although their work clearly contributes to guide local authorities and decision makers.

Another issue appeared when selecting findings in environmental research and trying to build pathways with the other domains. Contrary to those in health projects, these findings refer to changes and adaptations that are part of local peasants and farmers' daily strategies and constraints and are therefore well known by them. In other words, "what would the audience learn from these results?" However, the opportunity to share such findings interested the local actors participating to the preparatory discussions during which they could express their preoccupations and even suggest new avenues for research. For example, many representatives of peasants and farmers insisted on the need for more research on diseases attacking crops or animals.

\section{Communicating the results to a diversified audience}

From the beginning a consensus emerged within the organization committee that forum theatre shows should be used. Usually performed in sensitization programmes, forum theatre can be an extremely powerful tool to disseminate a specific message as well as to make people react (there is an extensive literature on the use of interactive theatre in health and development: see Morrison et al, 1991 for a more general reflection on the use of that media in West Africa and more recent research undertaken in different contexts and on a variety of topics from aging to reproductive health, and addressed to service providers, teachers and populations). In the specific case of HDSS, where many residents question the purposes of the longitudinal follow-up and the number of surveys conducted on more specific and often health oriented matters, four theatre sketches were performed to address these issues. The three first sketches respectively focused on situations occurring within each research domain: the respondents' lack of understanding regarding the demographic follow-up; residents' strong opposition to blood samples; peasants' surprise when seeing research teams working in their fields. The last sketch "wraped up" these issues with the performance of a group of men helding palavers on the HDSS research activities. The purpose of the theatre performance was thus to make the atmosphere lighter and to encourage a dialogue between the main actors - populations, field-workers and researchers. It was also meant to ease the transition to the slide show where findings were described more formally.

The slide show was designed following a detailed synopsis and entirely composed by photographs taken in the area, some older and representing past projects, other more recent showing the main changes occurred since the HDSS implementation. Over 60 photographs sampled in the IRD database and also taken for the purposes of the event by a professional photographer were gathered in a power point file to present the main results in demography, health and environment. For each slide a small text was written in French and then translated into sereer. The comment for each slide was read in situ by the two field-workers members of the organization committee of the event. This put a lot of pressure on them especially as they were not used to that tool. Hence, at first, the comments were said very fast with repetitions and unplanned bits and not always in accordance with the slides. However, as the evaluation will show, what appeared as not appropriate for skilled researchers embedded in their own communication biases, seemed highly appreciated by the audience.

Finally, after the slide show a period open to questions from the audience was scheduled. This period was meant to be an incentive for participants to directly address their preoccupations and questions to the researchers present in the audience. The consultations that had taken place during the 4 months prior to the event were supposed to have prepared the participants to formulate their questions and convinced them of the importance to ask them. However, most of the people who used the floor to question the researchers were local leaders or authorities (village chiefs, imams, local development actors and members of the administration) and in general men with the exception of some women active in associations. The evaluation will shed some light on the reasons why the "regular" participants were not inclined to intervene.

Each day went on with slight differences. The first day took place in Ngayokhem where the process was somehow tested. The theatre performance faced some logistic difficulties, the slides and the comments said in Sereer were not well articulated to each other as the commentators were not sufficiently trained yet. As a result, the question-answer period at the end was used extensively to clarify points. As the days went on, the theatre performance and 
the slide show were considerably improved and had a great success; as a result, the questionanswer period became less dynamic and increasingly focused on participants' acknowledgments of the work accomplished by IRD or their' complaints and expectations regarding future activities. It is worth noting that the third day that took place in Toucar was disturbed by a sand storm which made it necessary to move the whole meeting in a closed building rather than being held outside. As a result, many people who wanted to assist didn't find space in the room and had to stay outside trying to capture what was going on from the windows.

In the following sections we present the methodology and some preliminary results of this evaluation.

\section{Evaluating the process: Data and methods}

A month after the event, three groups of participants totalizing 99 people were asked to evaluate the whole process. These groups were:

1) 5 researchers who were part of the organization and those who were invited for the event; 2) 15 fieldworkers and key local informants, some involved in the design and organization of the event, some just part of the audience; and 3) a sample of 79 regular participants to each day. Using a qualitative design, we addressed three main dimensions: first, what were the questions and discussions the participant had before the event about the research conducted in the area? Second, were the topics addressed during the event of interest for the participants? Third were the communication tools appropriate to both feed and awake participants' interest? Finally, did the participant have discussions with other people about the event once over and did they disseminate the information gathered during the event?

In order to conduct the evaluation, three interviewers were hired, respectively in charge of one sector (see endnote iii and previous section). Table 1 below describes the characteristics of the sample and the approach used to gather the information. 46 qualitative interviews and 33 open-ended questionnaires were conducted among the 79 selected participants by three local fieldworkers and transcribed from Sereer to French by them. The interviews with the researchers and fieldworkers were conducted in French respectively with an outside researcher and with one member of the organising committee.

Table 1: Evaluation - The sample's characteristics

\begin{tabular}{|c|c|c|c|}
\hline & $\begin{array}{l}\text { Ngayokhem sector } \\
\left(1^{\text {st }} \text { day }\right)\end{array}$ & $\begin{array}{l}\text { Diohine sector }\left(2^{\text {nd }}\right. \\
\text { day) }\end{array}$ & $\begin{array}{l}\text { Toucar sector } \quad\left(3^{\text {rd }}\right. \\
\text { day })\end{array}$ \\
\hline Approach used & $\begin{array}{l}\text { Qualitative interviews } \\
\text { Recorded and } \\
\text { transcribed by the } \\
\text { interviewer }\end{array}$ & $\begin{array}{l}\text { Qualitative interviews } \\
\text { Written notes and } \\
\text { transcribed by the } \\
\text { interviewer }\end{array}$ & $\begin{array}{l}\text { Qualitative } \\
\text { questionnaires filled } \\
\text { by the interviewer and } \\
\text { handed for typing }\end{array}$ \\
\hline $\begin{array}{l}\text { Village chiefs and } \\
\text { their councillors }{ }^{\star}\end{array}$ & 2 & 5 & 8 \\
\hline $\begin{array}{l}\text { Teachers, school } \\
\text { heads, etc. }\end{array}$ & 3 & 2 & 4 \\
\hline Health agents ${ }^{\star \star}$ & 6 & 6 & 9 \\
\hline Religious leaders ${ }^{\star \star \star}$ & 1 & 5 & 1 \\
\hline $\begin{array}{l}\text { Women's groups } \\
\text { representatives }\end{array}$ & 1 & 4 & 5 \\
\hline $\begin{array}{l}\text { Agriculture and } \\
\text { farming groups } \\
\text { representatives }\end{array}$ & 1 & 4 & 2 \\
\hline $\begin{array}{l}\text { ASC - Association } \\
\text { culturelle et sportive } \\
\text { (youth, cultural and } \\
\text { sports activities) }\end{array}$ & 2 & 1 & 3 \\
\hline
\end{tabular}




\begin{tabular}{|l|c|c|c|}
\hline $\begin{array}{l}\text { Local political } \\
\text { advisers }\end{array}$ & 2 & 1 & 1 \\
\hline Total & 18 & 28 & 33 \\
\hline
\end{tabular}

*Among this group we also included field workers hired by IRD and living in the area and people working for administrative although non political institutions

${ }^{*}$ Within this group we find different actors: heads of dispensaries, nurses, community health workers, and bajenu gox a sereer expression referring to women doing sensitization in their community on reproductive health matters essentially.

${ }^{* * *}$ Both Muslim and Christian. If the Muslim religion is dominating the Senegalese religious landscape, the Sereer are characterised by a significant Christian influence dominated by the Catholics and more recently new religious communities such as "Les Assemblées de Dieu". However, this fairly traditional society (in the sense that despite people's mobility and access to modernity, they remain strongly attached to the land and their kinship ties) still cultivates its strong animist beliefs and practices leading to an interesting mixture with the monotheist religions.

The interviews are analysed using a thematic content analysis framework based on a codification grid entered in the NVivo software.

\section{Key results from the evaluation process}

In general, there is a consensus that the initiative of reporting scientific results in the Niakhar HDSS gathering a diversified audience was unique and innovative. The event was thus considered exceptional regarding both the content of what was reported back and the means used to do it.

\section{Participants' appreciation of the content that was reported back}

Participants were extremely satisfied with the fact that the issue of blood samples and clinical trials in health research projects was addressed. These activities have conducted to a strong opposition from several residents and continue to do so despite intense sensitization from local field workers and increased education levels among the population. Because most people do not fully understand the purposes justifying blood samples, they consider that the results should be individual and they expect more personalized reports. Because results are never disseminated at an individual level, a rumour has been ongoing that IRD is selling blood for lucrative reasons. Such a belief, in addition to the symbolic meanings of "taking blood out of the body", especially from children, is so embedded that researchers and physicians still face huge difficulties to convince the populations and the local leaders to accept to participate to projects that involve blood testing. The fact that this issue was addressed during the three days by both researchers and fieldworkers emphasizing the purposes of such activities, significantly improved participants' understanding of these research and medical processes. This highlights the pertinence of reporting findings back more directly to the population and/or its representatives rather than solely to local leaders and decision makers. Indeed, although all the HDSS residents were not gathered during these days, they were well represented by a variety of people belonging to and active in various social groups and domains. By selecting such a diversity of participants, the organizing committee wanted to make sure that the information would be spread more efficiently through the members of the community who could not participate.

Another innovation was the inclusion of research findings in the environmental field. Despite a huge amount of activities conducted by the IRD research staff in this domain for decades, most residents were simply not aware of these unless they were part of the projects. This can be explained by two reasons. First, HDSS were initially essentially designed to focus on child mortality and health before including a wider range of research areas and scientific disciplines. Second, findings in environmental studies are so embedded in people's daily lives that it does not necessarily appear as "research results" but more "facts" that the majority is aware of. For example, the lack of rain leading to droughts and bad harvest leading to peasants' strategies to innovate and find new ways of surviving is well known by most residents. However, becoming aware that IRD researchers are conducting an increasing number of studies in these domains has clearly surprised participants and has led to their hope that IRD would "find solutions" for their farming problems as they think it has regarding their children's health. This shows how reporting findings back to the populations should be done with great caution as there is a risk of increased expectations from people that might make researchers' work complicate. However, at the same time, as it also encourages a dialogue between populations and research teams, it might thus contribute to clarify populations' 
expectations with the explanations they get while leading them to provide new or more precise research orientations.

Almost systematically, respondents emphasized their satisfaction with the work accomplished by IRD (former ORSTOM) for decades regarding children's health. Although IRD is producing health and demographic data that is meant to guide health decision makers, the institution does not intervene directly. However, for people having witnessed the teams circulating around in coordination with vaccination programs it is extremely difficult to disentangle the respective roles of the various aactors at stake. Therefore, constant attempts were made during the days to clarify the IRD's mission and the purposes of the different data collection designs.

\section{The adequation of the communication means}

From the three communication means used (theatre, question-answer, and slide show) most of the participants found the theatre the most appropriate because of the direct contact it established with the audience. Like one fieldworker said "it is an ice breaker tool and it gives the message that IRD is looking for a way to communicate with the population". The slide show offered the opportunity for participants to remember certain studies and was an incentive for them to share memories. This medium thus created a relatively familiar atmosphere despite its greater formality compared to the theatre performance. However, some participants found it a little bit too rigid. Table 2 below synthesises the main perceptions regarding the communication means used to report results back.

\section{Table 2: Participants' appreciation of the different communication means}

Interestingly, the appreciations participants had on each communication tools used were generally quite different from those of the researchers present in the audience.

For example, the theatre performance was seen by researchers as an ice breaker because it was showing well known situations by residents in a funny way: for example, the fieldworker entering a compound with his questionnaire and being asked silly questions, etc. The theatre performance was not meant to inform or explain anything, on the contrary it was supposed to highlight the interrogations people have about the research process and thus make the transition to the more explanatory dimension of the slide show. Unexpectedly, the theatre performance was in fact almost systematically considered as being very informative, making clear what the IRD was doing and, in particular, that blood samples are done for populations' well being. Thus, it was through the 4 sketches that the audience could better grasp the research objectives and how the results can lead to potential actions, although no explanations were provided during the performance.

The slide show, on the other hand, was designed to clarify some findings in particular the 'path' from data collection to the results. While designing it, researchers made efforts to avoid graphs and tables, exclusively using photographs from the villages and selected situations and projects that were supposed to shed light on the worries and questions populations had regarding their purposes. They also tried to follow the usual rules of not 'talking too much' on each slide to avoid overwhelming the audience with information. After the first day the two Sereer speakers commenting the slide show took increasingly more control of the whole presentation and thus spent more time explaining each slide in their own words. They added details and highlighted the role played by IRD insisting on its scientific rather than intervention purpose. According to the researchers these comments appeared far too long, overwhelming for the audience who seemed to lose interest after a long period of listening to the comments while watching the photographs. In fact, the interviews made afterwards among a selection of participants show that a majority of them was extremely satisfied with the explanations provided during the slide show; these constituted an "added value" to the theatre performance and highlighted the importance of environmental studies which was a discovery for a majority of the audience. In other words, the more time was spent explaining in commentators' own language the purpose of the various types of projects and researches conducted for decades in the area, the more people understood and the more satisfied they were.

Finally, regarding the question-answer period, a slight difference between researchers' and participants' perceptions also appears. According to the former this part was expected to be the most "participatory" where the audience would be able to share its preoccupations and ask questions directly to the researchers, a fairly unusual situation for both groups. However, researchers felt it was the most "disappointing" part, where few questions showing participants' curiosity on the results and need to deepen their understanding were asked. Rather, it seemed to them a long litany of either 
acknowledgement for the "wonderful work" accomplished by IRD for decades and/or requests to provide assistance or to start new projects in specific domains such as adult health and agriculture or animal breeding. Nevertheless, most participants interviewed during the evaluation process said that they liked this possibility for exchanging ideas with the IRD staff, although they felt that in general the theatre and slide show had been so informative that they didn't have any questions or that the questions asked by others complemented well what they wanted to know. It is worth noting that several women said that they were not comfortable talking in front of a big audience and that they would have preferred to be in smaller groups or just among other women. Finally, other respondents said they felt they were lacking time to ask their question. This could be understood in different ways. It is true that some questions were in fact long comments said by local authorities such as village chiefs or religious leaders. Also, some 'real' questions led to long answers by the concerned researchers. And both the theatre performance and slide show took quite a long time so it is very likely that without expressing it, many participants were tired and not willing to extend the period.

This tells us two things. First, that expecting an active participation from the audience by making comments and addressing their questions to the research staff might be, at least in this context, unrealistic. In this society like in many other in sub-Saharan Africa, talking in public is a 'man's thing'. Therefore, despite the fact that during our preliminary consultations no women with whom we discussed said anything about separating groups by gender, it might be more appropriate to schedule "causeries" with different groups separated by age and gender after the theatre performance and slide-show. It is also worth considering the 'fatigue' of keeping the focus during a long period (approximately 2 to 3 hours) for people who are usually active in farming, domestic tasks, etc. This format may be too long. However according to most of our respondents, none of the different tools used should be removed. They were complementary and should be kept although perhaps with some modifications. Also it is likely that researchers' initiative to be more accessible to local residents was perceived by the audience as a positive sign of openness towards them and that it was enough for them. In other words, the questionanswer period remains a complementary and necessary part of the "restitution" process for the different actors (researchers, fieldworkers and populations) while scheduling parallel discussion groups or "causeries" with a sample of the participants soon after they watched the theatre performance and slide show appears as a more appropriate way to gather their interest and possible needs for more information.

Overall there was a consensus that such an event should occur more regularly to keep the population updated on what was going on in terms of research and the future they could expect from the presence of IRD.

Table 2: Participants' appreciation of the different communication means

\begin{tabular}{|c|c|c|c|}
\hline & Theatre performance & Slide show & $\begin{array}{l}\text { Question-answer } \\
\text { period }\end{array}$ \\
\hline $\begin{array}{l}\text { Positive } \\
\text { appreciation }\end{array}$ & $\begin{array}{l}\text { Very informative } \\
\text { Ice breaker }\end{array}$ & $\begin{array}{l}\text { Remembering some } \\
\text { studies } \\
\text { Emphasized the } \\
\text { environmental studies }\end{array}$ & $\begin{array}{l}\text { Complemented well the } \\
\text { questions they still had } \\
\text { after the theatre and } \\
\text { slide show }\end{array}$ \\
\hline $\begin{array}{ll}\text { Neutral } & \text { to } \\
\text { negative } & \\
\text { appreciation } & \end{array}$ & $\begin{array}{l}\text { Somehow a } \\
\text { unidirectional tool } \\
\text { which doesn't provide } \\
\text { the space for the } \\
\text { participants to express } \\
\text { their questions/worries }\end{array}$ & $\begin{array}{l}\text { Too long } \\
\text { Not always easy to } \\
\text { follow }\end{array}$ & $\begin{array}{l}\text { Everything was clear so } \\
\text { not useful } \\
\text { Too shy to talk in front } \\
\text { of many people (esp. } \\
\text { women) } \\
\text { Lack of time to ask }\end{array}$ \\
\hline
\end{tabular}




\begin{tabular}{|l|l|l|l|}
\hline & $\begin{array}{l}\text { about the research } \\
\text { activities }\end{array}$ & $\begin{array}{l}\text { questions and talk } \\
\text { The translation was too } \\
\text { often in Wolof rather } \\
\text { than in Sereer }\end{array}$ \\
\hline Observation & $\begin{array}{l}\text { Consensus in all } \\
\text { interviews and sectors }\end{array}$ & $\begin{array}{l}\text { Recalls investigators' } \\
\text { presence in the } \\
\text { research processes }\end{array}$ & $\begin{array}{l}\text { Several women did not } \\
\text { dare to intervene - } \\
\text { some asked for gender } \\
\text { separated events }\end{array}$ \\
\hline
\end{tabular}

\section{Participants' understanding and use of the information provided}

During the evaluation, questions were asked about the usefulness of the days for local professionals such as health workers, teachers, or authorities such as village chiefs and religious leaders.

First, especially local health workers specifically but also at a general level, participants gained a better understanding of the purposes of projects based on clinical trials and/or blood samples. Participants acknowledged that after the days they felt more comfortable because more knowledgeable to explain the reason and importance of such projects to their peers and their families.

For others who considered that they already knew enough, such as nurses or heads of dispensaries, these explanations were seen as very useful because it provides them as well as their own staff more appropriate words to convince sampled patients to participate to such studies.

Several participants told that they took the initiative to share what they had learnt with other residents later during ceremonies or meetings. Although it was never requested from them that they would have to disseminate the information they got during the three days, it is interesting to note that people shared the information on their own initiative. This clearly shows how important the information disseminated was for them and their awareness that non participants would also be interested.

Another interesting finding relates to some participants' request to be more involved in the process if it was rescheduled. In particular health workers such as bajenu gox (see endnote iv) who are extremely engaged in their community and know particularly well the realities faced by women regarding reproductive health, insisted that they should have been involved in the organization of the event, both logistically and by informing the potential participants. As a matter of fact, some participants did not really understand why the days were organized, while others were simply not aware of it, highlighting the importance of involving more local people in the organization.

Finally, the field workers hired on a permanent or regular basis like the DEMO team ${ }^{\mathrm{vi}}$ or temporarily by IRD had strong expectations on these days as they perceived it as the best way to facilitate their work when explaining to local participants the purposes and significance of a study to which they are solicited.

In addition to these positive reactions, several participants had requests that go beyond asking for any support or assistance. Due to the long lasting implementation of the HDSS in their area, people having specific social and professional position in the community asked for certain types of information. For example, teachers were requesting to get some educational documentation on the demographic changes in the area they could use for their classes. The head of the catholic primary school in one of the 3 main villages asked if he could have access to the statistical distribution of children of school age depending by religion to plan the classes of Catholic schools in the area. Village chiefs asked to have access to the lists of residents in their respective villages with basic sociodemographic information in order to be more aware of the potential needs they may have. Heads of health dispensaries wanted to have more information on the prevalence of certain diseases in the area and so forth. These expectations highlight the awareness people have of the existence of detailed data on themselves and their community and their need to share information with the researchers.

With a more systematic dialogue between populations, fieldworkers and researchers, such needs will become increasingly expressed. This will inevitably lead researchers to get more 
involved in the sharing of results and information. Therefore, they will have to address the unavoidable ethical issues regarding confidentiality in small settings such as the villages composing the Niakhar HDSS.

\section{Discussion: the challenges of a participatory approach in a HDSS context}

Despite the success of the event shown by participants' satisfaction, several avenues for improvement appear, all pointing to the need to adopt a more efficient participatory approach. Also, it is essential to conduct a second evaluation later on in order to capture what is left from the event in the collective memory and how it is/not affecting residents' daily lives and perceptions regarding the ongoing research activities.

A first avenue relates to the local key informants who should be involved in the design of the whole process. The activities were organized by a team composed by researchers and by the local fieldworkers most familiar with these researchers. This inevitably created a bias in both the subjects to be addressed as well as the design of each activity. In addition, these field workers, part of the DEMO team, were all men, and despite their extensive experience of the area and having witnessed many different situations, it has led to a gender bias in the content reported back: very little on reproductive issues or on social changes that affect women's lives such as new marriage patterns, girls working in the cities, etc. Most of the content was oriented towards the most visible scientific activities, essentially related to children's health and, increasingly, to farming and climate change.

Another issue relates to how participants were recruited. In the main villages where the days were taking place, some neighbourhoods had been neglected and thus poorly or not represented at all. None of the organizing team members or the different local key informants hired to assist the organizing committee had thought in terms of space but rather in terms of social status and role in the community.

More importantly, a consensus emerged among the participants, that the whole population should have been informed about the event even if not invited. The team feared that if the event was too much publicized, residents of whole villages would want to participate and that it would be overwhelming. However, most participants affirmed that with clear explanations that the activities would be held for just a sample of people, the local population would have accepted this (with a few exceptions) and waited for feedback from them. This highlights the gaps between researchers' and residents' perceptions regarding the way a major event will be understood locally.

Logistically a little "commotion" occurred with a misunderstanding regarding the transportation of the participants. First, people were informed that IRD would pick people up in the villages with their own cars and buses. Then, realizing that it would be far too costly and complicated, it was decided that people would come using local transportation but would be reimbursed. Despite the efforts of the organizing team to inform the invited guests, some people did not get the information and thus never arrived as they were waiting for the cars. Beyond the anecdotal aspect of this misunderstanding, it tells us that in the particular context of long lasting HDSS such as Niakhar, it can be very easy to create small conflicts or frustrations. The fact that IRD has been present for decades both eases and complicates things: eases because in general people are more open to participate to different activities as they see the institution contributing to health improvements in the area; complicates because expectations are high and therefore, people can be fairly sensitive to the way researchers and HDSS leaders behave.

The 'lesson' we can draw from the evaluation is that, because of the inevitable distance between researchers and their field despite their commitment to the HDSS, they can end up with a fairly mistaken view and perception of how people may react. Therefore, it appears essential to diversify the key informants who will be involved in the organization of the activities as well as introduce a new culture of participatory approach in a field where medical and demographic research practices have dominated for decades.

\section{Conclusion: implication for future research programs and policies}

Confirming the findings in the 2006-2007 project using a participatory approach to design events where scientific results are reported back directly to the populations appears pertinent in different ways. First, it leads to a constant dialogue between researchers, fieldworkers and populations (or their representatives) regarding their respective perceptions of what a research priority is. Second, the communication means, especially the theatre performance and the slide show should be designed by a more localized committee in order to make sure residents' key preoccupations regarding the research activities are addressed. Finally, the evaluation process should be conducted in two steps: a first one 
soon after the event and the second one later, perhaps a year afterwards. The evaluation process conducted a month after the event allowed participants to address certain critiques to the way the event was designed thus providing the opportunity for researchers to improve it for the future. Nevertheless, there was a consensus that such an event should occur on a more regular basis and be addressed to all residents (see Hertrich et al, 2011).

Participation or participatory approaches are part of the increasing number of international development buzzwords (Cornwall, 2005, 2007). In many cases one limitation of these approaches is that participation is never really achieved. One clear demonstration of the potential gaps between populations, fieldworkers and researchers relates to how they respectively perceived each phase of the day they participated to (theatre, slide show and questionanswer period). Obviously populations and researchers have significantly different time frames while fieldworkers are torn between their wish to well disseminate the information to the former while not opposing how the latter wants to design the whole event. So when researchers tend to think "brief, concise and synthestic", locals preferred detailed information with enough time to absorb it.

Therefore, "thinking participatory" is challenging for all levels of the HDSS staff as it involves a different "research culture". After the experience in Niakhar several avenues for improving the whole process can be identified:

About the recruitment of participants with the participation of a greater diversity of actors including the identification of "less visible" key informants; these may not have a particular professional or social function but may nevertheless have a certain authority and leadership in the area.

About the content: taking into account people's preoccupations can provide incentives for researchers to address new fields of inquiry.

About the communication tools: if all tools have generally led to the enthusiasm of participants, the theatre appears as a 'must'. The fact that the company hired was local, spoke the same language was essential. However, more work hand in hand with local field workers and also perhaps a sample of the populations' representatives could considerably improve the performance and lead to more reactions and potential discussions among the participants.

The last issue to be addressed is how to ensure that such a process will be re-conducted, updated, and how often it should occur. In the case of HDSSs, if such events are scheduled on a regular basis and are evaluated, not only would the information be disseminated at various levels but also it is could be better appropriated by individuals and groups. Hence, reporting scientific findings back in the fields of population, health, environment and other key development issues could also complement and reinforce sensitization programs in contributing to behavioural changes targeted in international and national policies at the local level. Therefore, reporting scientific results back using a participatory design should be included in every project and seen as a key moment of the research process of collecting valid and valuable data. And this is particularly true for long lasting programs such as HDSS' longitudinal follow-ups.

\section{Bibliography}

Cornwall, A. and K. Brock, 2005. "What do buzzwords do for development policy? A critical look at 'participation', 'empowerment' and 'poverty reduction"', Third World Quarterly, 26(7): 1043-1060

Cornwall, A., 2007. "Buzzwords and fuzzwords: deconstructing development discourse", Development in practice, 17(4-5): 471-484

Delaunay et al, 2013. "Profile. The Niakhar Health and Demographic Surveillance System", International Journal of Epidemiology, 42: 1002-1011

Gravois Lee R. \& Theresa Garvin, 2003. « Moving from information transfer to information exchange in health and health care », Social Science and Medicine, 56(3): 449-464.

Hertich V., M. Lesclingand, M. Quaglia and A. Stephan, 2011. "Constructing a survey over time: Audio-visual feedback and theatre sketches in rural Mali", Demographic Research, 25(22): 695-722

Madhavan Sangeetha, Mark Collinson, Nicholas W. Townsend, Kathleen Kahn and Stephen M. Tollman, 2007. "The implications of long term community involvement for the production and circulation of population knowledge", Demographic Research, 17(13): 369-388

Massé, R. 2003. "Valeurs universelles et relativisme culturel en recherche internationale : les contributions d'un principisme sensible aux contextes socioculturels." In : Doris Bonnet (éd), Paris : Autrepart, Revue de I'Institut de Recherche pour le développement (IRD) éditions de l'Aube, (28) : 21-35.

Mondain N., E. Bologo and P. Arduin, 2010. 'Exploring respondents' understanding and 
perceptions of demographic surveillance systems in Wester Africa: methodological and ethical issues", African Population Studies, 24(3): 149-165

Mondain N. and E. Bologo, 2009, "L'intentionalité du chercheur dans ses pratiques de production des connaissances: les enjeux soulevés par la construction des données en démographie et santé en Afrique", Cahiers de recherche sociologique, $48: 175-203$

Morrison, J.F., 1991. « Forum Theater in West Africa: An Alternative Medium for Information Exchange", Research in African Literatures 22(3): $29-40$

Olivier de Sardan, J-P., 2014. « Des restitutions, pourquoi faire ? ", in C. Dayer, M-N. Schurmans and M. Charmillot, La restitution des savoirs, L'Harmattan, Logiques sociales, p.37-50

Riley, N. and J. McCarthy, 2003. Demography in the age of the postmodern, Cambridge

Notes

i The 2006-2007 funded by the Indepth network was addressing populations' perceptions about the research conducted among them as well as about their interest in being informed of the related results in 5 HDSS in West Africa in Senegal and Burkina Faso. It reflected strong ambivalence among participants were torn between the feeling that the research was positive for their community and their discomfort in not understanding the purposes of the multiple research activities conducted longitudinal follow-up and additional studies on a sample of the HDSS total population.

ii Verbal autopsies are used to identify the cause of death of a person in countries where such information is not systematically collected, thus complicating the tasks of health actors to better target groups at risks and specific illnesses. The procedure consists in interviewing a close member of the family or any other person who had a close relationship with the dead and get as much detailed information as possible on the context and conditions of the symptoms and agony.

iii Each sector corresponds to one main village and the satellite villages (generally around 10) which depend on the main village's health dispensary.

iv A bajenu gox (sereer) is usually a woman who is in charge of sensitizing women in her village or neighbourhood depending on the size of the village on various reproductive health matters. Each bajenu gox has to write a report and hand it to the midwife of the dispensary she depends on regularly and these reports are sent to the health district.

v 4 additional qualitative interviews were conducted by another field-worker with two of the organization committee researchers.

vi The longitudinal follow-up is conducted by a team of 7 field workers, all men, who live in the area and most of them native from there. Two of them are permanent whereas the others are on contract depending when the follow up takes place: once a year, every three months, or any other time each year. 